https://www.amerabra.org; https://fspu.uitm.edu.my/cebs; https://www.emasemasresources.com/

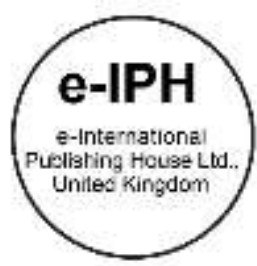

\title{
Design Thinking Mini Project Approach using Factor Analysis
}

\author{
Sharifah Zannierah Syed Marzuki ${ }^{1}$, Che Asniza Osman'1, \\ Siti Zahrah Buyong ${ }^{1}$, Mohamad Zreik ${ }^{4}$ \\ ${ }^{1}$ Faculty of Business and Management, Universiti Teknologi MARA, \\ Puncak Alam Campus, Malaysia \\ ${ }^{2}$ Central China Normal University, No. 152, Luoyu Road, 430079, Wuhan, Hubei, People's Republic of China \\ szannierah@uitm,edu.my, asnizaosman@gmail.com, siti280@uitm.edu.my, mohamadzreik1@gmail.com \\ Tel: +603-3258 7042
}

\begin{abstract}
This study used factor analysis to investigate relationships between educator to student interactions, the relationship between students, skills to critical thinking, and motivation. Factor analysis showed that there are three factors; passion, assistance, and guidance. Meanwhile, the adequacy is 0.945 surpassing the recommended value of 0.50 using Kaiser Meyer Olkin. The statistical significance of Bartlett's Test of Sphericity test indicated that 0.00 and $\mathrm{X} 2=3552.973$. Adequacy measurement of Anti-Image Correlation Matrix ranges from 0.49 to 0.69 . It is significantly important that educators guide the students in becoming more creative and innovative by using and applying DTMP during the learning process.
\end{abstract}

Keywords: design thinking;creative;innovative;factor analysis

eISSN: 2398-42870 2021. The Authors. Published for AMER ABRA cE-Bs by e-International Publishing House, Ltd., UK. This is an open access article under the CC BYNCND license (http://creativecommons.org/licenses/by-nc-nd/4.0/). Peer-review under responsibility of AMER (Association of Malaysian Environment-Behaviour Researchers), ABRA (Association of Behavioural Researchers on Asians/Africans/Arabians) and cE-Bs (Centre for Environment-Behaviour Studies), Faculty of Architecture, Planning \& Surveying, Universiti Teknologi MARA, Malaysia.

DOI: https://doi.org/10.21834/ebpj.v6i17.2797

\subsection{Introduction}

Design Thinking (DT) has been a preferred pedagogy in Social Sciences and Science and Technology clusters in higher learning institutions. Dym, Agogino et al. (2005) have studied the relevancy of embedding design thinking, teaching, and learning in engineering education, thus graduating engineers who can design. The survey highlighted that project-based learning is the most favoured pedagogical model along with other assessments. Gambrell (2001), as cited in Rugutt and Chemosit (2009, stated a significant role between students' involvement and academic achievement. Here, the relationship between students, students and educators, and skills related to critical thinking appear to be significant concerning motivation. The focus of this study is to know the acceptance of the Design Thinking Mini Project (DTMP) as a teaching and learning tool, particularly in institutions of higher learning like Universiti Teknologi MARA (UiTM), as the study that focuses on DTMP is very limited.

The study examines whether DTMP has a relationship with student-to-student, student and educator, and critical thinking skills by integrating motivation. DTMP is a tool that enables students to interact with other students and educators in conducting mini-surveys on the market potential of their imagination or some with a working prototype. Students can perform better when encouraged by the educators in the teaching and learning environment.

eISSN: 2398-4287O 2021. The Authors. Published for AMER ABRA cE-Bs by e-International Publishing House, Ltd., UK. This is an open access article under the CC BYNCND license (http://creativecommons. org/licenses/by-nc-nd/4.0/). Peer-review under responsibility of AMER (Association of Malaysian Environment-Behaviour Researchers), ABRA (Association of Behavioural Researchers on Asians/Africans/Arabians) and CE-Bs (Centre for Environment-Behaviour Studies), Faculty of Architecture, Planning \& Surveying, Universiti Teknologi MARA, Malaysia.

DOI: https://doi.org/10.21834/ebpj.v6i17.2797 


\subsection{Design Thinking}

It is important to note that traditionally, designers emphasized adding more value to product features and usage (Brown \& Wyatt, 2010). DT embraces consumer feedbacks in detail, and this prototype is further developed to fulfill beyond expectations. It is gathered from the concept that DT has prominent values that address potential buyers' needs. Business organizations take DT seriously because it contributes added values in becoming more unique, stands up differently, and has the advantage. Dorst (2011) supported this and highlighted that DT had been widely accepted and seen as an exciting new paradigm in dealing with problems. Design thinking requires critical thinking skills, and both support each other. As mentioned above, DT is a preferred style of teaching that add value. In another aspect, critical thinking is providing new ideas and provide solutions. The combination serves as a new paradigm in learning.

In addition, problems can be converted into opportunities when professional designers create something valuable from the investigation and thus provide beneficial outputs to the organizations and practitioners in other fields. Strategists consider the DT concept to build creative ideas as creativity is stimulated from imagination and contribution of ideas and contributes to innovation in an organization (Wattanasupachoke, 2012). His survey found that the application of DT to business operations has significantly enhanced the firm's innovativeness. He reasoned that the DT technique starts from generating customers' information and combining it with the employees' creative ideas.

DT supports all activities about considerable knowledge in different perspectives in developing ideation and thus help the creative conversion of the knowledge and skills in coming up with a new creation (Kröper et al., 2010). Their study concluded that the notion of motivation has a prominent role in pursuing tasks that involve learning, experimentation, and creative play make-believe kind of situation. This links to this study on the Design Thinking Mini Project (DTMP) that looks into the relationship between student-to-student, educatorto-student, and critical thinking skills concerning Motivation Theory. This theory has been widely discussed and appeared to be a prominent aspect of student success where it influenced students' involvement and academic achievement (Gambrell, 2001).

\subsection{Student-to-Student Relations}

A study done by Rugutt and Chemosit (2009) revealed that the student-to-student relationship proved to be one of the significant predictors of student motivation. Students engaged themselves during learning activities through behaviors and thus feel motivated. It appeared that active students remained motivated, supportive. and willing to participate in academic activities. However, those who were less motivated seemed to be less engaged. On another note, the environment and facilities must also be very supportive of creating awareness and interest among students. Dunne and Martin (2006) stated that managers are interested in design methods. Business students must be competent enough to comply with the requirements, and business schools need to provide courses for the approaches.

Motivation appears directly relate between students' involvement and academic achievement (Gambrell, 2001). With this, innovative teaching methods should be embedded in the pluralistic approach in education. This study focuses on the Design Thinking Mini Project (DTMP) that supports the stages in new product development. This approach has seen a positive outcome among students, as highlighted in a study by Syed Marzuki et al. (2018). It is found out that DTMP has implications for the continued development of the study. The researchers expected that this kind of approach in teaching and learning would provide a platform for future enhancement and strategies to motivate learners to be more creative and innovative, thus stimulating the idea of out-of-the-box thinking. With this, it can be enhanced and contribute to innovation in an organization. Furthermore, the DT approach has its step-by-step approach for the students to develop innovative products and services.

The relationship between students has a significant connection with motivation. It can be combined with critical thinking skills to develop what educators would require them to do. Furthermore, other individuals are supported those include faculty members and education stakeholders, and institutional facilities and environment (Rugutt \& Chemosit, 2009). It is interesting to note that the increased demand for clear and definite knowledge about design thinking in companies has made it significant to be implemented in universities. Well-trained educators and peers must guide the students to adopt and apply the design practices

\subsection{Educator-to-Student Interactions}

Educators have their style in dealing with encouraging students when imparting knowledge. Nurturing a positive classroom environment and creating motivation among students is essential (Rugutt \& Chemosit, 2009). Within this context, design is widely practiced and to be the central activity of engineering. Graduate engineers should have these skills and the ability to design effective solutions (Sheppard, 2003). This shows the integration of the analysis that can be useful for usage in the real world. It is called reverse engineering that helps to improve students' systems thinking in converting ideas, research, prototypes to functional products and services (Dym et al., 2005).Many researchers argue that students in the 21 st century need more than just the traditional learning method in entrepreneurship. Since entrepreneurship education is a complex process, educators need a transition to teach the subject using new techniques. Stovang and Nielsen (2015) pointed out that the traditional way poorly associate students with activities and projects. There seems to be a missing link in between the theoretical findings and the entrepreneurship goals. A suitable method that has brought researchers' attention to teaching entrepreneurship is design thinking.

DT is defined as an investigative and creative method involving a person in gathering information, experimentation, creating of physical models, and redesign (Linton \& Klinton,2019).

Due to technological evolution, students need to be taught differently. Students who come from a sciences and technology background need to have different skills. Essentially, they need to be creative, think innovatively, and cognitively evaluate business opportunities. DT method is also known to be the possible future of entrepreneurial education because of its many compatibilities that include creativity, motivate confidence, and innovative mindset. The benefits of using design thinking are while maintaining the introductory course, the process is flexible for any situation of use (Stovang \& Nielsen 2015), and practitioners can design their contexts (Glen et al., 2014). 
The current situation demands institutions of higher learnings to facilitate the development of competencies and skills among students of multidiscipline. To support this, well-trained educators in DT are required to provide effective teaching-learning (Carrol,2014). Trained educators are equipped with metacognitive competencies, attitudes, values, and action skills (Scheer et al., 2012). Their knowledge is crucial to ensure positive interaction with their students and create a more supportive learning method that would advance students' developmental, emotional and educational needs.

The interaction in DTMP between an educator and students using the design thinking approach in entrepreneurship education is seen as very significant. Within this context, educators' competencies affect students' learning performance. The pedagogical interactions of educators and students' participation are essential in the learning activities of academic achievement. Costa et al. (2014) showed that learning performance is positively related to student's academic achievement. Indirectly both were influenced by educator competencies and student-student interaction. Young et al. (2003) explained that students absorb more knowledge when motivated and fascinated in the course and when teaching methods match their likings. Thus, it is essential to have a constructive teacher-student relationship (Arthur, Gordon, \& Butterfield, 2003).

Positive student-teacher interactions and relationships are the entryways to learning. Educators who interact with such affection, safe, share real experience, up-to-date teaching methods, and close relationships would allow students to be independent learners. Relationships are the crucial point to motivating them (Costa et al., 2014). Research's study revealed that when students can accept learning openly, culture of accountability and personal meaning for learning tend to develop within them. It is also important for educators to interact with students of the 21st century with enhancing skills by way of new pedagogy like design thinking, system thinking, and teamwork skills (Razzouk \& Shute, 2012). Design thinking is a practical approach. It reconnects educators to their resourcefulness and goals for supporting students to mature as deep thinkers, problem solvers, and innovators. Carroll (2014) highlights some vital characteristics of a design thinking educator include: inspiration, sound authority, well-defined role, able to build a good relationship, build rapport and develop positive student team culture.

Leitão and Waugh (2007), in their study, claimed that teachers' relationships with students involve three dimensions, there are of connectedness, availability, and communication. In another qualitative research by Tu, Liu, \& Wu (2018), 86 percent of the students, when asked to compare traditional teaching and DT, find that the latter method provides more opportunities to interact with their educators and peers. From the above discussion, further research on educator and students' interaction using the pedagogy of design thinking in entrepreneurship education is necessary. Design thinking is a new learning environment that would enable students to develop critical thinking skills and creativity in empathizing situation, defining problems, providing innovative solutions, prototyping, and analyzing.

\subsection{Critical Thinking Skills}

The relationship between students and between educators and students involves critical thinking skills (Rugutt \& Chemosit, 2009), thus increasing the class's involvement and leads to positive academic change. Furthermore, their study has shown that critical thinking skills are important variables in predicting motivation. This is supported by Kröper et al. (2010), which highlighted on past studies have exposed the many effects of problem solving, creativity and emotions. An interesting excerption by the founder of the Positive Deviance Initiative and a professor at Tufts University, Jerry Sternin in Brown \& Wyatt (2010, p. 32) on design thinking and creativity:

"Design thinkers look for workarounds and improvise solutions and find ways to incorporate those into the offerings they create. They consider what we call the edges, the places where "extreme" people live differently, think differently, and consume differently."

Here, the DT process has orderly steps; inspiration, ideation, and implementation. These three notions include encouragement to develop solutions where thinking of new ideas combines producing, improving, and experimenting with ideas. In this context, implementation connects the project stage into people's lives (Brown \& Wyatt, 2010). DT has many values to offer, including looking at creativity and aesthetics in every operational process and not just creating looks of the products (Wattanasupachoke, 2012).

\subsection{Motivation}

It is vital to combine DT with business studies and strategic analysis. Companies are competing in offering innovative products and services, and a lot of them are making full use of the DT process in their daily operations. Wattanasupachoke (2012) mentioned innovativeness as an essential element for a firm competitive advantage. Innovativeness leads to differentiation advantage and higher performance. In realizing this, motivation is considered a powerful force. Motivation has been a distinctive element in performing a task (McDevitt \& Ormrod, 2004).

Theory of Human Motivation stated that the needs of various behavior in motivations are essential and consider all aspects of certain kinds of behavior (Maslow, 1942). Additionally, some behavior is highly motivated, and some are weakly motivated. With this, an interaction between educators and students are highly demanded in this DTMP. A pluralistic approach must be embedded, not only in normal kind of interaction or lectures but significant changes in the curriculum like teaching of design thinking as the new way of teaching approach.

\subsection{Methodology}

The respondents in this study were the students of Science and Technology clusters in Universiti Teknologi MARA (UiTM) who took Technology Entrepreneurship subject (ENT 600). The students came from various faculties that include Faculty of Applied Sciences, Faculty of Health Sciences, Faculty of Sports Science \& Recreation, and Faculty of Architecture, Planning \& Surveying. The relationship between students are seen very significant due to the fact that they know each other as classmates. They are required to be in different groups for this mini project and discussed on type of invention or innovation that they intend to do. This survey has administered the 
questionnaires using Google form taking into considerations on the Covid situation. Desk research and critical review pertaining to the topics have provided in-depth explanations in building up the questionnaire. A pilot test has been conducted in order to improvise the instrument.

The number of students who participated in this survey is 254 , and they represented a broad array of individuals from different programmes and backgrounds that served interesting findings. Students responded to a set of questions using five Likert scales that has the ranging from coding $1=$ strongly disagree to coding $5=$ strongly agree that asked them on educators and student interaction (Part $A)$, relationship between students (Part B), skills in relating to critical thinking (Part C), motivation (Part D) and demographic (Part E).

\subsection{Findings}

According to Mulaik (2010), factor analysis is about variables and supported by Pallant (2007) that information is combined to connect a set of variables. Within this context, it is vital to identify the factors involved during the analysis Hutcheson and Sofroniou (1999). They reasoned that it could give in-depth meanings with respect to the connections in the data. Pallant (2007) added that a large set of variables could be divided into a smaller set of factors. In contrast, Hair et al. (2006) stressed that factor analysis could define a data matrix that has underlying factors. Pallant (2007) and Grimm \& Yarnold (2005) emphasized that large sample size is more relevant and reliable. A sample size of 254 was gathered and appeared to be relevant with respect to the technique as mentioned earlier.

It is gathered here the result of factor analysis in the DTMP approach. As mentioned earlier, this study is very significant as the studies that concentrated particularly on DTMP is extremely limited. Table 1 shows the measure of sampling adequacy is 0.945 exceeding the recommended value of 0.50 using Kaiser Meyer Olkin. It shows that the result has great value. In addition, the statistical significance of 0.00 , which indicates the $x 2=3552.973$, is shown from the test of Bartlett's Test of Sphericity. Within this context, a measure of sampling adequacy for individual variables from the Anti-Image Correlation Matrix ranges from 0.49 to 0.69 . The responses to the survey form were subject to a Principal Components Analysis with a Varimax rotation, and the results of the analysis appear in Table 1.

Table 1: KMO and Bartlett's Test

\begin{tabular}{lll}
\hline Kaiser-Meyer-Olkin Measure of Sampling Adequacy..945 \\
\hline Bartlett's Test of Sphericity & Approx. Chi-Square & 3552.973 \\
\cline { 2 - 3 } & Sf & 171 \\
\cline { 2 - 3 } & Sig. & .000 \\
\hline
\end{tabular}

Using Kaiser's criterion of retaining factors with eigenvalues greater than one, three interpretable factors were obtained from the analysis. This was then compared to the scree plot, a graph of each eigenvalue (Y-axis) against the factor related with (X-axis) as proposed by Catell (1966). By looking at the point of inflection of the scree plot, it can be gathered that the data has three underlying factors. Thus, the analysis produced three factors where the total variance explained was $68 \%$, with all eigenvalues being over one. The title given to each factor is named and described below. With cut off value of 0.65 for inclusion of a variable in interpretation of a factor, 16 of 19 variables did not load on any factor.

\subsection{Reliability Analysis}

A critical aspect in determining each criterion for each factor is the eigenvalue. An eigenvalue of more than 1.0 is applicable. Validity and reliability can be tested using internal consistency analysis (Cronbach a). Sekaran (2000) highlighted that when Cronbach's alpha value is near one, the greater the internal consistent reliability. In essence, Nunnally (1978) reiterated that factor loading must exceed 0.6 to ensure that a significant level has convergent validity. Table 2 indicated that The Cronbach's a values for all dimensions range from 0.85 to 0.92 , which exceeds the minimum a of 0.6 (Hair et al., 2006); thus, the measure of the constructs is deemed reliable.

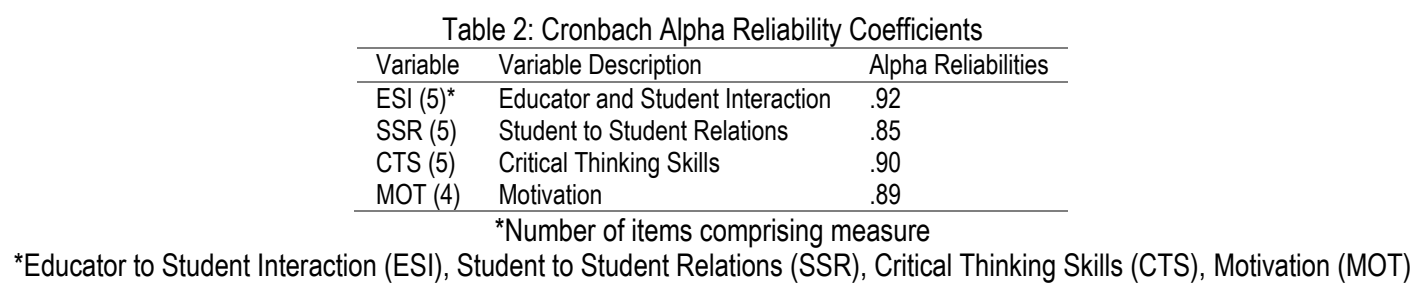

\subsection{Discussion}

Three items are identified to have values below 0.3 . Low communality values of less than 0.3 indicate that the variables do not fit well with the variables in their component and should be removed from the scale. As a rule of thumb, only variables with loadings of 0.32 and above are interpreted (Tabachnick \& Fidell, 2007). Therefore, the greater the loading, the more the variable is a pure measure of the factor. This criterion for the significance of factor loadings is agreed by Hair et al., (1995) that considered the loadings of 0.30 as significant only for sample sizes of 350 or greater. Considering both suggestions, factor loadings of 0.65 is selected although this study has a sample size of 254 that is near to 350 . In order to interpret the choice of cut-off value for the size of loading, Tabachnick and Fidell (2007) mentioned that it is upon the researcher to make the decision. 
1. The first factor, Factor 1, consisted of "Passionate" that highlighted lecturers' desire to deliver DTMP. It showed that the highest variance explained is $10.26 \%$ and evidenced that the respondents felt that lecturers/educators represent an essential factor in DTMP.

2. Factor 2 showed "Assistance". This dimension indicated that lecturers would attend to problems and give ideas to the students to proceed with the next step. Here, it is gathered that the variance explained is $8 \%$. Respondents expect that educators play a vital role in learning and experimenting with the DTMP.

3. Factor 3 indicated "Guidance" and it appeared that lecturers need to be attentive in ensuring students to follow the guidelines of DTMP. This particular factor explained $6.39 \%$ of the variance.

Table 3: Factor Loadings for Scale Items

\begin{tabular}{lccc} 
& Passionate & Assistance & Guidance \\
\hline The lecturer has passion in guiding DTMP & 0.89 & & \\
The lecturer helps me when I have trouble with DTMP & & 0.66 & \\
The lecturer moves about the class to guide me & & & 0.77 \\
\hline Variance explained (percentage) & 10.26 & 8.00 & 6.39 \\
\hline
\end{tabular}

\subsection{Conclusion \& Recommendations}

Regulatory focus on problem solving, creativity, emotions, motivation, and creation have been revealed from past studies. Using descriptive statistical analyses, factor analyses, internal consistency (Cronbach Alpha) reliability analyses of instrument subscales and factor analysis, this study sets out to explore the effect by testing whether the interactions between student-to-student and educator-to-student and critical thinking skills are affected by motivation. Results suggest that educators contribute to the student learning environment thus, DTMP has an impact that encourages students to express their ideas with guidance from the educators and market survey. Educators seem very passionate with their work, contribute ideas and guide the students/learners to enhance the learning development.

As mentioned above, a market survey is also one of the stages embedded in the design thinking approach to make DTMP as tangible and factual as possible. DT is an interesting tool that emphasizes interaction between a firm and customers and encourages them to participate in every ctitical step before a product/service is developed (Wattanasupachoke, 2012). It started with the data collection process, where customers contribute their ideas, comments, and suggestions on product ideation or concepts or prototypes. This is to foresee the commercial possibility and mitigate risks. DTMP has a direct relationship with educators and learners, and the factor analysis showed that three groups had produced: passion, assistance, and guidance. These three factors generate the students' creative thinking skills and motivation to learn and apply what is being taught. The implications of this findings are that students are motivated to work together and discuss the invention or innovation they will create. The output being delivered will be transformed into assignments on new product development and business blueprint. Students are eager to know how far the products or services they have created can be finalized and can be produced in reality and generate values. Apart form this, this research has some limitations that include the students who have participated are from the Science \& Technology (S\&T) faculties and did not cover the rest of the programmes in Universiti Teknologi MARA as the subject of Technology Entrepreneurship (ENT 600) is only offered to S\&T students. Furthermore, the research took place during the starting of the pandemic and classes were occasionally being on hold. Here, research limitations can be looked into by future research efforts. It is hoped that future research explores DTMP on Social and Science students and includes more variables into the research framework. For example, it is good to test the role of real entrepreneurs in DTMP to be more hands-on and fulfill the needs and wants of the actual market.

\section{Acknowledgements}

The authors would like to extend their appreciation to the Institute of Research Management \& Innovation, Universiti Teknologi MARA (UiTM) for the awarded research grant with the project code: 600-IRMI 5/3/LESTARI (034/2018). Sincere thanks go to all respondents who have taken part in the survey despite the pandemic issue of COVID 19. Finally, the authors are particularly thankful to the Faculty of Business and Management, UiTM, for the support and encouragement given during the completion of this research.

\section{Paper Contribution to Related Field of Study}

The DTMP creates a significant interaction between educator and student and integrate with critical thinking skills and motivation. The three factors that include passion, assistance and guidance appear to be relevant during this study.

\section{References}

Arthur, M., Gordon, C., \& Butterfield, N. (2003). Classroom management: Creating positive learning environments. Southbank, Victoria: Thomson

Brown, T., \& Wyatt, J. (2010). Design thinking for social innovation. Stanford Social Innovation Review, 31-35.

Carroll, M. (2014). Learning from what doesn't work: The power of embracing a prototyping mindset. Retrieved from web.stanford.edu/group/redlab/cgibin/publications_resources.php. 
Costa, C., Cardosob,A. P., Margarida PedrosoLimac, M.P., Ferreirad, M. \& Abrantese, J. (2014). Pedagogical interaction and learning performance as determinantsof academic achievement. Procedia - Social and Behavioral Sciences. 171 ( 2015 ) pp $874-881$.

Dorst, K. (2011). The core of 'design thinking' and its application. Design Studies, 32(6), 521-532.

Dunne, D., \& Martin, R. (2006). Design thinking and how it will change management education: An interview and discussion, 5(4), 512-523.

Dym, C. L., Agogino, A. M., Eris, O., Frey, D. D., \& Leifer, L. J. (2005). Engineering design thinking, teaching and learning. Journal of Engineering Education, $103-120$.

Glen, R., Suciu, C., \& Baughn, C. (2014). The need for design thinking in business schools. Academy of Management Learning \& Education, $13(4), 653$.

Grimm, L. G., \& Yarnold, P. R. (2005). Reading and understanding multivariate statistics. Washington: American Psychological Association.

Hair, J. F., Anderson, R. E., Tatham, R. L., \& Black, W. C. (1995). Multivariate data analysis (4th ed.). New Jersey: Prentice Hall.

Hair, J. F., Black, W. C., Babin, B. J., Anderson, R. E., \& Tatham, R. L. (2006). Multivariate data analysis (6th ed.). New Jersey: Prentice Hall.

Kaiser, H. F. (1974). An index of factorial simplicity. Psychometrika, 39, 31-36.

Kanfer, R., \& Ackerman, P. L. (1989). Motivation and cognitive abilities: An integrative/aptitude-treatment interaction approach to skill acquisition. Journal of Applied Psychology, 74(4), 657-687.

Leitão, N., Waugh, R. F. (2007). Students' views of teacher-student relationships in the primary school. A paper presented at the 37th Annual International Educational Research Conference, held by the Australian Association for Research in Education at Fremantle, Western Australia

Linton, G \& Klinton,M.(2019) University entrepreneurship education: a design thinking approach to learning. Journal of Innovation and Entrepreneurship, 8(3).

Maslow, A. H. (1942). A theory of human motivation. Cambridge University.

Pallant, J. (2007). SPSS survival manual. Sydney: McGraw-Hill.

Razzouk, R. \&Shute, V. (2012). What is design thinking and why is it important? Review of Educational Research, September 2012, 82(3), pp. 330-348.

Ruggut, J., \& Chemosit, C. C. (2009). What motivates students to learn? Contribution of student-to-student relations, student-faculty interaction and critical thinking skills. Education Research Quarterly, 32 (3), 16-28.

Rugutt, L. B. (2001). What we know about motivation to read. In R. F. Flippo (Eds.), Reading researchers in search of common ground (pp. 129-143). Newark, DE: International Reading Association.

Scheer, A.,Noweski, C.. \& Meinel,C. (2012). Transforming constructivist learning into action: Design thinking in education. Design and Technology Education: An International Journal, [S.I.], 17(3)

Stovang, P., \& Nielsen, S. L. (2015). DesUni: University entrepreneurship education through design thinking. Education +Training, 57(8/9), 977-991.

Syed Marzuki, S. Z., Osman, C. A., Buyong, S. Z., Mohammad Kamaruddin, L. (2018). Design Thinking Mini Project: Think Innovatively In Novel Ways. International Conference On Teaching And Learning (ICOTAL 2018), 20-21 February 2018, UiTM Cawangan Melaka, Kampus Bandaraya (KBM).

Tabachnick, B. G., \& Fidell, L. S. (2007). Using multivariate statistics (5th ed.). Boston: Pearson Education, Inc.

Tu,J.C., Liu, L. X. \& Wu, K. Y. (2018). Study on the learning effectiveness of Stanford design thinking in integrated design e ducation. 10, 2649.

Wattanasupachoke, T. (2012). Design thinking, innovativeness and performance: An empirical examination. International Journal of Management and Innovation, 4(1), 114.

Wylant, B. (2008). Design thinking and the experience of innovation. Massachusetts Institute of Technology Design Issues, 24(2), 3-14.

Young, M., Klemz, B., \& Murphy, J. (2003). Enhancing learning outcomes: The effects of instructional technology, learning styles,instructional methods, and student behaviour. Journal of Marketing Education, 25 (2), 130-142 